\title{
Intra-abdominal fibromatosis with vesico-colonic fistula: case of a benign disease running a malignant course
}

\author{
Dr. Padma Krishnaswamy, ${ }^{1}$ Dr. Manjunath Ramarajapalli, ${ }^{1}$ Dr. Sundari Nandyal ${ }^{1}$
}

Keywords: Fibromatosis, desmoid tumor, ureteric compression, hydronephrosis, vesico-colonic fistula

\begin{abstract}
Intra-abdominal fibromatosis is a rare benign tumor which can pose challenges in its management because of its local aggressive invasion and propensity for high recurrence. Here we report the case of a young woman who presented with a large intra-abdominal tumor with bilateral ureteric compression. This case highlights the risks of surgical intervention, the limitations of radiotherapy and subsequent complications that can develop over the years in such patients.
\end{abstract}

${ }^{1}$ M.S.Ramaiah Medical College, Bangalore

\section{Introduction}

Deep fibromatosis or aggressive fibromatosis (also called desmoid tumor or musculo-aponeurotic fibromatosis) is a rare, locally aggressive, monoclonal fibroblastic proliferation arising from the musculo-aponeurosis. It is characterized by local invasion and a high rate of local recurrence, but without any metastatic potential. The tumor, lacking a capsule, infiltrates along fascial planes and invades adjacent neurovascular structures.
Fibromatoses are rare, representing $<3 \%$ of all soft tissue tumors, with an estimated incidence of 2-4 new cases per million per year. ${ }^{1}$ Depending on their location, they are classified as extraabdominal, abdominal or intraabdominal, and the latter have been sub-classified further into mesenteric or pelvic fibromatosis. Fibromatosis is more frequently seen over the torso and the extremities. Between $37 \%$ and $50 \%$ of the aggressive cases occur in the abdominal region. They occur frequently between the ages of 25 and 35 years (range of 10-40 years) and are slightly more common in women than men (1.2:1).

With their relentless infiltration of surrounding structures, often involving vital structures, they present management challenges that defy easy answers and usually require a multimodality approach. Herein we present a case report of a patient with intraabdominal fibromatosis who had a high morbidity both during surgery and the subsequent follow-up. This case

Please cite this paper as: Krishnaswamy $P$, Ramarajapalli M, Nandyal S. Intra-abdominal fibromatosis with vesicocolonic fistula: case of a benign disease running a malignant course. Proc Obstet Gynecol. 2013;3(3): Article 3 [ 14 p.]. Available from: http://ir.uiowa.edu/pog/. Free full text article.

Corresponding author: Padma Krishnaswamy, M.S.Ramaiah Medical College, Bangalore, India. padmamsrmc@gmail.com.

Copyright: (c) 2013 Krishnaswamy et al. This is an open-access article distributed under the terms of the Creative Commons Attribution License, which permits unrestricted use, distribution, and reproduction in any medium, provided the original author and source are credited. 
highlights the aggressive nature and malignant-like course of this disease.

\section{Case report}

A 25 year old woman with two children was evaluated in 2004 at a Cancer Institute for an abdominal mass of two years duration. Her abdominal ultrasound was reported as a leiomyoma of the posterior wall of the uterus, with sarcomatous changes. Fine needle aspiration cytology had revealed a benign spindle cell neoplasia. Subsequent laparotomy findings demonstrated a stony hard mass of $20 \mathrm{x}$ $15 \mathrm{~cm}$ arising from the right broad ligament and pelvic bone and infiltrating the right lateral pelvic wall and sacrum. Due to adherence of the tumor to the surrounding structures, any further procedure was not pursued. She had refused radiotherapy and further followup.

She presented to us in June 2006 with abdominal discomfort due to the mass, which was gradually increasing in size. There was no history of abdominal pain or bowel, bladder or menstrual disturbances.

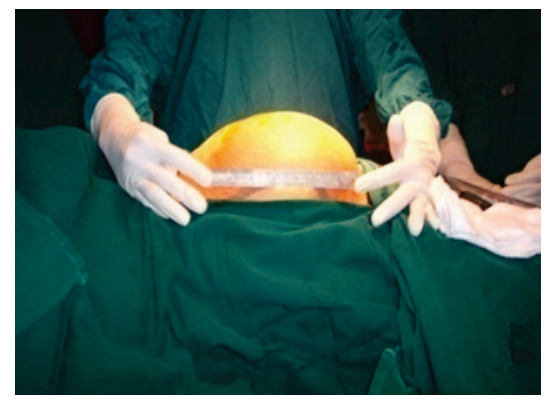

Figure 1. Preoperative extent of the abdominal mass

On examination, there was an irregular, fixed mass with varied consistency in the hypogastric, umbilical, right lumbar and right iliac areas corresponding to a uterine size of 28 gestational weeks (approximately $28 \mathrm{~cm}$, Figure 1). The cervix was attenuated by the mass. Uterus was not felt separately.

\section{Investigations}

Ultrasound demonstrated a tumor with solid and cystic components. Uterus and ovaries were not visualized. There was bilateral hydronephrosis. Subsequent CT scan reported a tumor with both solid and cystic areas not arising from the bone; the tumor was only partly separated from the iliopsoas. Uterus was deviated to the left; both ovaries were not visualized, and there was a moderate degree of bilateral hydronephrosis.

Renal function tests were normal. Colonoscopy showed normal mucosa.

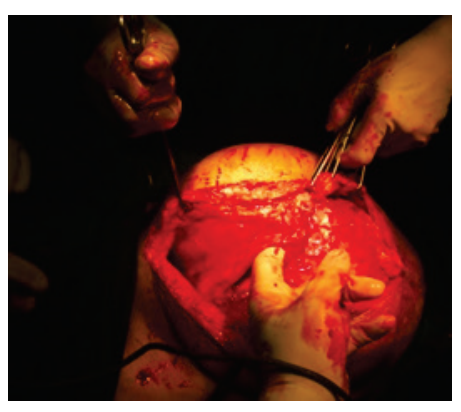

Figure 2. Separation of the tumor from the abdominal wall during surgical debulking.

In view of patient's discomfort and bilateral hydronephrosis, she was taken up for laparotomy after adequate counseling. There was a $20 \times 20 \times 15$ $\mathrm{cm}$ bosselated mass of heterogeneous consistency and as we proceeded to 
debulk the tumor, we saw it infiltrating the dome of the bladder, periosteum of the pubic arch, right iliopsoas, and sacrum. (Figure 2)

In addition, the uterus was pushed to the left. The left fallopian tube and ovary were normal; right adnexal structures were not visualized. The tumor encased the small bowel, right ureter, right common iliac, and the external and internal iliac vessels. The tumor was removed from the posterior aspect of the symphysis pubis, iliac crest, anterior abdominal wall, and iliopsoas. Debulking necessitated hysterectomy as well as right ureteric resection and anastomosis, repair of the resected dome of bladder, and repair of small bowel injury. The posterior aspect of the tumor encasing right iliac vessels was not removed. During surgery, the patient was adequately transfused with packed red cells and fresh frozen plasma. Histopathological analysis of the tumor resulted in a diagnosis of fibromatosis, predominantly fibro-collagenous tissue with intervening benign spindle-shaped cells resembling myofibroblasts. (Figure 3)

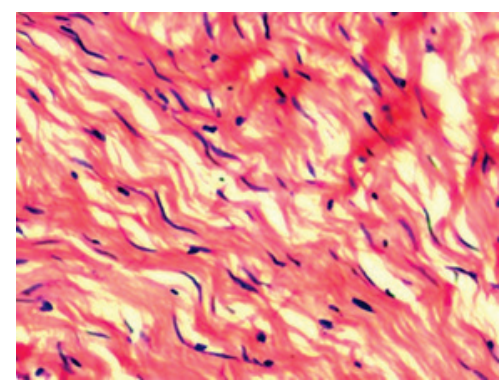

Figure 3. Histopathology showing bland sheets of cells indicative of fibromatosis.

Patient had a difficult post-operative period due to sepsis, which was managed medically. The patient refused radiotherapy for residual disease. She was discharged after three weeks in satisfactory condition with advice for regular follow-up.

The patient was on irregular follow-up. In a visit in 2008, she had a hard, fixed right iliac fossa mass. Ultrasound showed a solid, hypo echoic mass of $9.5 \times 6.1 \mathrm{~cm}$ adherent to the right pelvic wall with mild bilateral pelvicalyceal dilatation of the kidneys. The right kidney was smaller and showed parenchyma thinning. In view of a large recurrent tumor within two years of surgery (Figure 4), she received external RT using 3-D CRT technique with 5000 cGy/25 fractions/5 days per week.

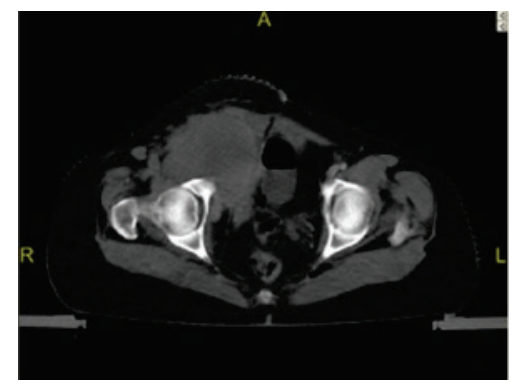

Figure 4. Recurrence of tumor observed during CT prior to radiotherapy

The patient presented in 2010 with burning micturition and fecaluria. Abdominal examination showed that the tumor in the right iliac fossa had decreased, measuring about $5-6 \mathrm{~cm}$. Ultrasound demonstrated a small right echogenic kidney with dependent debris in the urinary bladder. The post-void volume was $135 \mathrm{ml}$. Urine examination showed fecal matter. Renal function 
tests were normal. The nature of the fistula was investigated. Intravenous urogram showed pooling of contrast in the region of the right iliac fossa on the delayed scan, and a vesico-ileal fistula was inferred. On cystoscopy, a fistulous opening of approximately $5 \mathrm{~cm}$ at the 8 o'clock position was visualized near the bladder neck. The cystogram demonstrated the contrast entering the ascending colon; a diagnosis of vesicocolonic fistula was made. Two options were discussed with the patient: 1) surgical intervention, which was predicted to have a very high morbidity due to the unresectability of the tumor; or 2) conservative management. A plan of regular follow-up with symptomatic treatment was agreed upon.

This patient has been since seen irregularly. In August 2012 and again in May 2013, she presented with easy fatigability. She had a persistent hard mass of $6 \mathrm{~cm}-7 \mathrm{~cm}$ in the right iliac fossa. Ultrasound scan showed bilateral medical renal disease but renal function tests were normal. She was treated with antibiotics for her urinary tract infection and required blood transfusions for her symptomatic severe anemia during both of these visits.

\section{Discussion}

Intra-abdominal fibromatosis is a rare soft tissue tumor whose etiology remains elusive. Researchers have attributed various predisposing factors, including trauma, previous surgeries, estrogen exposure, and a genetic predisposition. The increased incidence in women of reproductive age suggests an association of this disease with the endogenous hormonal environment.
Desmoids and Familial Adenomatous Polyposis (FAP)

Familial adenomatous polyposis is an autosomal dominant condition in which numerous adenomatous polyps are seen in the colon and rectum. A variant of FAP, Gardner's syndrome, presents with extracolonic manifestations like desmoid tumors, osteomas and epidermoid cysts along with a predisposition to thyroid and periampullary carcinomas. $^{2}$ An association of intra-abdominal desmoids with familial adenomatous polyposis of the colon and Gardner's syndrome has been well documented. They occur more frequently in FAP patients, with an incidence of $3.5 \%-32 \%$, and about $2 \%$ of patients presenting with desmoid tumor have FAP. The FAP patients with intra-abdominal desmoids present at a younger age, often before the fourth decade of life and are more likely to have advanced or complicated disease. ${ }^{3}$

Mutations of the adenomatous polyposis coli (APC) gene are thought to be responsible for the development of FAP. In both FAP and non-FAP desmoid tumors, mutations of the APC gene on the long arm of chromosome 5 have been implicated. Desmoids occurring in FAP patients are often associated with germline mutations in the APC gene, whereas sporadic desmoids have somatic mutations in the APC gene or in the beta-catenin gene. In the cellular environment of these tumors, where either APC or beta-catenin is mutated, there is a loss of ability to degrade betacatenin, which accumulates before it translocates into the nucleus. ${ }^{4}$ Betacatenin subsequently activates the $\mathrm{T}$ cell factor, which in turn causes transcription of target genes. One of the 
target genes for activation is cyclooxygenase-2. This gene's activity contributes to tumorigenesis by inhibiting apoptosis, stimulating angiogenesis and invasiveness, and modulating cell proliferation by increasing the expression of growth factors such as platelet-derived growth factors (PDGFs). ${ }^{5}$

Our case was a young woman with no previous history of surgery, estrogen supplementation, or a family history suggestive of such tumors.

\section{$\underline{\text { Pathology }}$}

Arising from the myofibroblasts, the macroscopic appearance of desmoid tumors is firm and rubbery. It is characterized by a relatively homogenous incised surface of white and greyish network of bundles resembling scar tissue with relatively poor vascularization. Large desmoid tumors may undergo mucoid or cystic degeneration. ${ }^{6}$ Histologically, the tumor usually has a poorly circumscribed pattern and is composed of proliferating stellate to spindle cells arranged in long fascicles or whorling patterns with bland nuclear features. The cells usually show no nuclear atypia or hyperchromasia.

Immunohistochemistry may aid in ruling out other possibilities. Desmoid tumors stain positive for vimentin and variably positive for smooth muscle actin or other muscle-specific markers like desmin. Beta-catenin is extremely useful in distinguishing from other spindle cell neoplasms. Nuclear staining for betacatenin is positive in at least $80 \%$ of sporadic desmoids, with some studies demonstrating $98 \%$ nuclear staining. ${ }^{7}$
The differential diagnosis of intraabdominal fibromatosis includes gastrointestinal stromal tumor (GIST), solitary fibrous tumor, inflammatory myofibroblastic tumor, sclerosing mesenteritis, and retroperitoneal fibrosis or an underlying malignancy, such as a lymphoma. $^{8}$ Intra-abdominal desmoids are most commonly misdiagnosed as gastrointestinal stromal tumors (GIST), but the presence of nuclear beta-catenin supports a diagnosis of desmoids, although a minority of GIST may demonstrate some nuclear beta-catenin positivity. Additional stains may be used to distinguish between these two, such as C-KIT or DOG-1 (Discovered On GIST-1). c-KIT and DOG-1 are positive in GIST, but negative in desmoids, though an infiltrate of mast cells within desmoids can result in positive c-KIT staining pattern. Histologically, idiopathic retroperitoneal fibrosis may look similar to desmoid tumors, but the hyalinized collagen is more prominent with a typical lymphoplasmacytic infiltrate; they do not stain for betacatenin. $^{3}$

Desmoid tumors express hormone receptors and most of them express estrogen receptors $\beta$ (ER $\beta)$ rather than estrogen receptor (ER $\alpha)$, making a case for hormonal manipulation in their management. In our patient, immunohistochemistry or genetic studies were not done due to financial constraints.

\section{Clinical presentation}

Patients with intra-abdominal fibromatosis are usually asymptomatic in the earlier course of the disease. Pelvic fibromatosis may present as slowly growing palpable masses, which 
are asymptomatic initially and often mimic ovarian neoplasms. ${ }^{6}$ In advanced disease, patients complain of pain, discomfort, constipation, vomiting, abdominal mass, weight loss, and symptoms due to organ compression. Specific complications reported are ureteric stenosis, ${ }^{9,10}$ ureteric fistula, ${ }^{11}$ bowel obstruction, ${ }^{12}$ and bowel perforation. $^{13}$ Our patient initially presented with an abdominal mass to another hospital but refused radiotherapy there. She presented to us when there was progressive increase in its size and abdominal discomfort.

\section{Clinical course}

Clinically, desmoid tumors are marked by phases of growth and progression, stabilization, and sometimes spontaneous regression. It is difficult to predict the clinical course of desmoid disease in any particular patient. However, in the context of FAP, it has been found that desmoids are the worst in young nulliparous women. It has been reported that, in over 100 FAP patients with desmoid disease, $10 \%$ experienced complete regression of their tumor and $7 \%$ died from aggressive, unresponsive disease; the remaining $83 \%$ experienced variable growth but were not severely affected. ${ }^{14}$

\section{Management}

When a desmoid tumor is diagnosed, a thorough family history, examination, and colonoscopy should be performed in order to diagnose or rule out familial adenomatous polpyposis. ${ }^{15}$ Patients with FAP and intra-abdominal desmoids tend to have more severe disease and increased recurrence rates. Even if colonoscopy is initially normal, these patients are recommended for routine surveillance with colonoscopy.

The management involves various options of surgery, radiation, nonsteroidal anti-inflammatory drugs, antiestrogens, cytotoxic chemotherapy and targeted therapies, which are used singly or in combination. Choosing an optimal therapy for desmoid tumor is difficult. The disease has a varied presentation and usually requires a multi-modality approach. In addition, there are no randomized or prospective trials for the different treatment options because of its rarity. Whatever treatment is chosen, recurrence rates are high and range between $30 \%$ and $40 \%{ }^{16}$

\section{Surgery}

When feasible, desmoids are treated by surgical resection with a wide margin. Complete resection of the tumor with negative microscopic margins is the standard surgical goal. However, the disease can recur even with complete surgical resection and is not shown to affect survival. The overall surgical strategy is therefore aimed at an attempt at complete removal using functionpreserving approaches to minimize major morbidity. ${ }^{16}$

The surgical management of intraabdominal desmoids requires a judicious approach to prevent morbidity. The extensive involvement of the mesentery limits the extent of resection and could predispose to significant morbidity, including complications of bowel ischemia, adhesions, and resultant obstruction, and even fistulae formation. ${ }^{17}$ Surgery often involves extensive resection, including bowel resection and anastomosis, 
hemicolectomy, enbloc removal of ureters and bowel with reanastomosis, colostomy or even intestinal transplant. Palliative surgery for intra-abdominal desmoids is hazardous, with a perioperative mortality rate of $10 \%$ to $60 \%$ (usually from blood loss), and can result in further tumor progression. ${ }^{18}$

These observations have led to conservative management being advocated over initial resection for patients with FAP or with large slow growing desmoids involving the mesentery or encasing vessels and organs. ${ }^{19}$ In the Dutch registry of FAP, the outcome of intra-abdominal desmoids was similar with a surgical versus nonsurgical medical approach (absence of progression in 33\% versus $49 \%$ at 10 -year follow-up). ${ }^{20}$ However, surgical resection is indicated with symptomatic disease that involves visceral organs that will soon be affected functionally and rapidly-growing desmoids.

In our patient, surgery was chosen in view of the increasing desmoid size, patient discomfort, and the progressive bilateral ureteric compression. Although our surgical team consisted of a gynecologist, gynecologic oncologist, surgical oncologist and urologist, complete resection of the tumor was not possible due to its proximity to the pelvic vessels. This case highlights the need for a multidisciplinary care team in a tertiary set-up to tackle the threateningly high morbidity when surgery is indicated.

\section{Radiotherapy}

Desmoid tumors are sensitive to radiation and it is an effective primary therapeutic option for patients with extra-abdominal disease who are not good surgical candidates, those who decline surgery, and those for whom surgical morbidity would be excessive. ${ }^{16}$ The recommended dose of radiation for definitive therapy is 50-60 Gy in 5-7 weeks at 1.8-2 Gy per fraction. Earlier studies demonstrated that radiotherapy alone or surgery combined with radiotherapy results in better local control $(78 \%$ and $75 \%)$ than surgery alone $(61 \%) .{ }^{21}$ However, a more recent study reported that the rate of local control between the groups receiving only surgery, only radiation, and a combination of both was not statistically different. $^{22}$

In intra-abdominal desmoids, the altered anatomy and adherence to the bowel can increase radiation toxicity. This makes radiation therapy a dangerous choice in this location and generally is advised as a last resort.

Neoadjuvant (pre-operative) radiotherapy may increase resectability and reduce rates of local recurrence in extra-abdominal desmoids. However, this is not considered standard therapy as its usefulness has not been confirmed by large prospective randomized trials. ${ }^{16}$

\section{Medical therapy}

A better understanding of the pathogenesis and behavior of desmoid tumors has paved the way for systemic therapies and a wait-and-watch policy. Candidates for systemic therapy include patients with extra-abdominal desmoids with multiple locoregional recurrences despite adequate local therapy, patients who have progressed and are no longer amenable to surgery or radiotherapy, and patients undergoing initial treatment 
of large intra-abdominal desmoids, especially those associated with familial adenomatous polyposis. ${ }^{16}$

Systemic treatment approaches in desmoid tumors include antihormonal therapy (tamoxifen, and selective estrogen receptor modulators/SERMs), non-steroidal anti-inflammatory drugs (sulindac, indomethacin), chemotherapy (single or combination therapy with methotrexate, doxorubicin, dacarbazine, vinblastine, and vinorelbine), and tyrosine kinase inhibitors (imatinib, see Table 1). Even though response rates of $50 \%$ or higher are reported, the true objective regression rates with these agents are in the range of $10 \%-15 \%$. Another $25 \%$ of patients experience minor shrinkage or tumor stabilization. ${ }^{18}$ The maximum effects are often not realized for several months, and the evaluation of systemic therapies becomes rather complicated, especially in a tumor that can have spontaneous growth arrest and variable growth patterns.

Tamoxifen: High-dose tamoxifen (120$200 \mathrm{mg} /$ day) is reported to be more effective than lower doses of 10-40 $\mathrm{mg} /$ day ${ }^{23}$ However, there are no randomized data supporting the extended use of higher doses, and the risk for secondary neoplasia and deep venous thrombosis could be greater with its use. In general, the true regression rate with tamoxifen is in the $15 \%$ to $20 \%$ range, with another $25 \%$ to $30 \%$ of patients achieving symptomatic improvement with stabilization of disease, resulting in a clinical benefit rate of up to $50 \%{ }^{24}$

Non-steroidal anti-inflammatory drugs (NSAIDS): Sulindac or indomethacin result in a variable response rate of $37 \%-57 \%$. However, most of these reports are single cases that achieved disease stabilization. ${ }^{16}$

Cytotoxic chemotherapy: Chemotherapy with cytotoxic agents may be an appropriate choice for patients with rapidly growing tumors or for patients who are highly symptomatic. Different regimen combinations with doxorubicin, liposomal doxorubicin, ifosfamide, and methotrexate plus vinca alkaloid have been used, producing significant responses ranging from $50 \%$ to $80 \%$ (partial responses or stable disease for at least 6 months). ${ }^{16}$ The side-effects of this regimen have to be balanced with the severity of the disease.

Targeted therapies: Imatinib is yet to be evaluated for its long-term efficacy. In cases with large and difficult-tooperate desmoids, a trial of neoadjuvant imatinib is found to be reasonable before surgical resection. ${ }^{16}$

Currently, most guidelines for systemic therapy recommend a stepwise approach, starting with NSAIDs (preferably sulindac). If this is not effective, hormonal therapy is added, most commonly consisting of tamoxifen or toremifene. Fast growing desmoid tumors not responsive to these agents are treated by cytotoxic chemotherapy or surgery. ${ }^{25}$

\section{Management of vesico-colonic fistula}

The development of vesico-colonic fistula occurring either due to the disease process or as a complication of radiotherapy affected the quality of life in our patient. The management of vesicoenteric fistulas requires surgical 
therapy aimed toward resolution of the primary process and abnormal communication as a single or two-stage procedure. However, in debilitated patients with reasonable life expectancy, a palliative colostomy may be considered. In very debilitated or unresectable diseases, an expectant and supportive medical management including conservative treatment with intermittent antibacterial treatment may be all that is possible. ${ }^{26}$ In our patient, the high morbidity associated with a second surgery along with the relentless progression of the disease decreased enthusiasm for surgical intervention.

In our case, the size of the tumor and the bilateral hydronephrosis with increasing patient discomfort prompted us to proceed with surgery after a patient-shared decision. The operative morbidity encountered encourages us to explore the possibility of using systemic therapy either as a primary or in a neoadjuvant setting to reduce tumor size when dealing with desmoids involving vital structures. Successful treatment of hydronephrosis due to massive mesenteric fibromatosis by using cyclo-oxygenase 2 inhibitors without surgical removal of the mesenteric fibromatosis has been reported. There was modest improvement in hydronephrosis and mesenteric fibromatosis with long-term celecoxib used $200 \mathrm{mg}$ twice daily. ${ }^{27}$

Radiotherapy either as a primary modality or as an adjunct to surgery in intra-abdominal desmoids would require a cautious approach.

Figure 5. Treatment algorithm for desmoid tumors (Adapted from Reference 29)

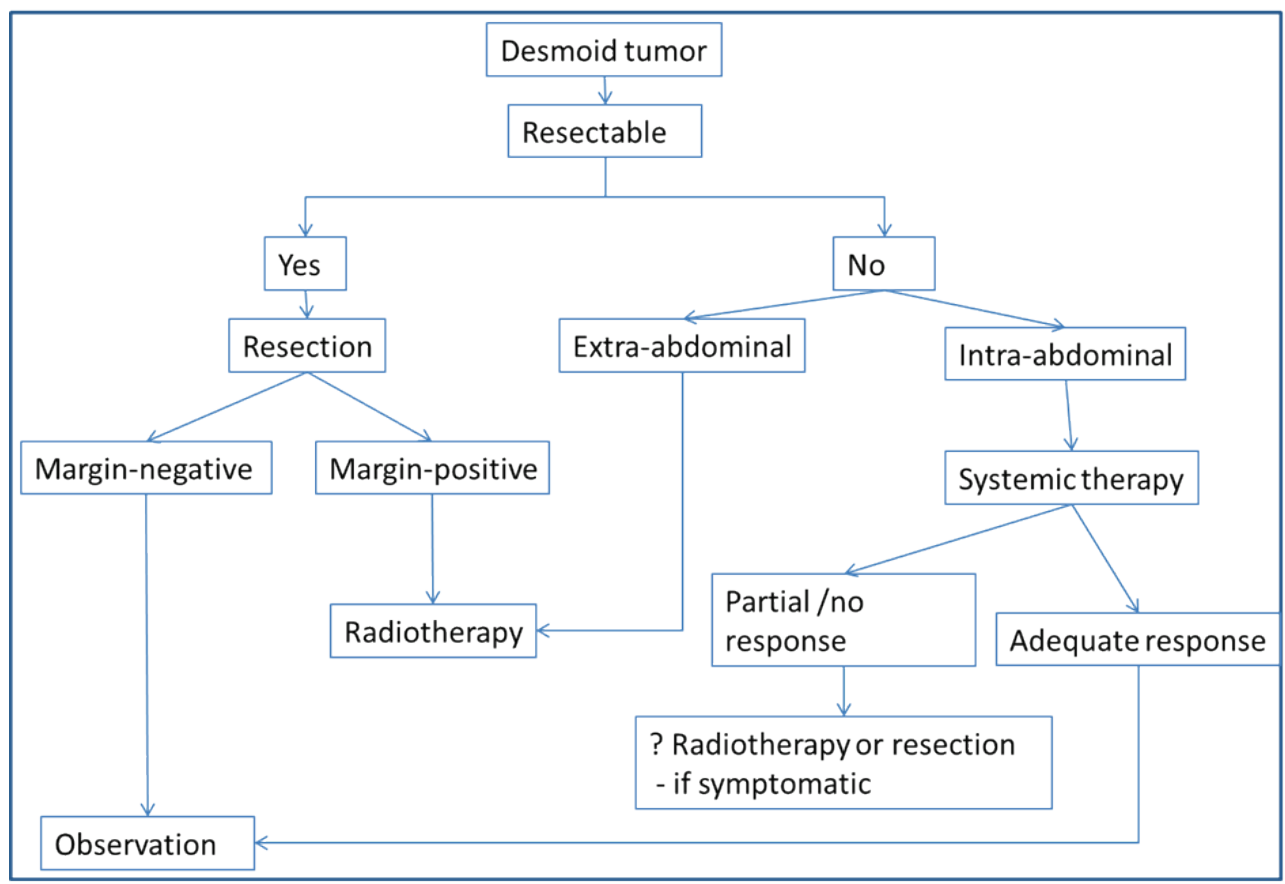




\section{Summary of management of desmoid tumors}

The treatment of aggressive fibromatosis has evolved over the last 10 years due to a better understanding of the disease. The roles of routine, aggressive first-line treatment of radiotherapy or surgery have now become debatable. There is a consensus that aggressive treatments that take their indications from retrospective studies should be reevaluated in the light of new data. ${ }^{28}$ Most guidelines recommend an individualized approach in the management of desmoid tumors. We have summarized the currently available possible treatment course in desmoid tumors. The flowchart in Figure 5 and the strategies in Table 1 provide direction to optimizing the treatment of desmoid tumors. ${ }^{29}$

Table 1 - Treatment strategies for desmoid tumor (adapted from ref. 16).

\begin{tabular}{|l|l|}
\hline Treatment & Indication \\
\hline Surgery & $\begin{array}{l}\text { Standard first line-treatment (in many cases), } \\
\text { moderately effective for symptomatic relapse, not } \\
\text { routinely recommended in FAP* with abdominal } \\
\text { desmoids }\end{array}$ \\
\hline Active surveillance & Small relapse without functional compromise \\
\hline Radiation & $\begin{array}{l}\text { Medical or technical contraindication for surgery, } \\
\text { possibly neoadjuvant before surgery }\end{array}$ \\
\hline $\begin{array}{l}\text { Tamoxifen and/or nonsteroidal anti-inflammatory } \\
\text { drugs }\end{array}$ & $\begin{array}{l}\text { First line in indolent disease if systemic treatment is } \\
\text { indicated }\end{array}$ \\
\hline Imatinib & $\begin{array}{l}\text { Second line in indolent or moderately symptomatic } \\
\text { relapse, possibly neoadjuvant before surgery }\end{array}$ \\
\hline Other agents & $\begin{array}{l}\text { Case reports on several agents, i.e., interferon- } \alpha, \\
\text { possibly for young women wishing to avoid } \\
\text { chemotherapy }\end{array}$ \\
\hline Cytotoxic chemotherapy & $\begin{array}{l}\text { Aggressive disease, especially intra-abdominal } \\
\text { presentation, doxorubicin single agent or combinations }\end{array}$ \\
\hline
\end{tabular}

*FAP, Familial adenomatous polyposis

\section{Intra-abdominal desmoids}

The Collaborative Group of the Americas on Inherited Colon Cancer has developed a staging and treatment system that stratifies intra-abdominal desmoids tumors based on prognosis. This staging system integrates size (in largest diameter), symptoms, and growth rate to predict prognosis and determine treatment. ${ }^{14}$ As described in Table 2, small $(<10 \mathrm{~cm})$, stable, and asymptomatic tumors can be monitored (Stage 1); small, symptomatic tumors should be resected (Stage II), when feasible; large $(10-20 \mathrm{~cm})$ symptomatic or large slow growing $(<50 \%$ increase in 6 months) / asymptomatic tumors require medical therapy (Stage III); and large $(>20 \mathrm{~cm})$ or rapidly growing or complicated desmoid tumors are likely to require radical resection and urgent intervention (Stage IV). 
Table 2 - Clinical staging of intra-abdominal desmoids (adapted from ref. 3)

\begin{tabular}{|l|l|l|l|l|}
\hline Stage & Size & Symptoms & Growth & Treatment recommendation \\
\hline I & $<10 \mathrm{~cm}$ & Asymptomatic & Stable & Observation +/-NSAIDS \\
\hline II & $<10 \mathrm{~cm}$ & Mild symptoms & Stable & $\begin{array}{l}\text { NSAIDS +/- anti-estrogen drugs, } \\
\text { resection }\end{array}$ \\
\hline III & $10-20 \mathrm{~cm}$ & Moderate symptoms & $\begin{array}{l}\text { Slow } \\
\text { growing }\end{array}$ & $\begin{array}{l}\text { NSAIDS +/- anti-estrogen drugs, } \\
\text { Cytotoxic therapy }\end{array}$ \\
\hline IV & $>20 \mathrm{~cm}$ & Severe symptoms/complications & $\begin{array}{l}\text { Rapid } \\
\text { growing }\end{array}$ & Resection \\
\hline
\end{tabular}

Mildly symptomatic $=$ sensation of mass, pain, but no restrictions; moderately symptomatic $=$ sensation of mass, pain; restrictive but not hospitalized; severely symptomatic = sensation of mass, pain; restrictive and hospitalized.

The risk of recurrence after intra-abdominal desmoid excision, especially with FAP, ranges from $50 \%$ to $80 \%$ and it is recommended that surgery be followed by prophylactic sulindac.

\section{Conclusions}

The management of desmoid tumors is multidisciplinary with the various available multimodality treatment options. Treatment is based on resectability and symptomatology. The management of intra-abdominal desmoid tumors requires a more cautious approach as both surgery and radiotherapy can adversely affect patient's survival or quality of life. Caution is required at every step of the treatment due to the potential morbidity of any chosen therapy, be it surgery, radiation, or systemic therapy.

\section{References}

1. Reitamo JJ, Scheinin TM, Häyry P. The desmoid syndrome. New aspects in the cause, pathogenesis and treatment of the desmoid tumor. Am J Surg. 1986 Feb;151(2):230-7. http://dx.doi.org/10.1016/00029610(86)90076-0 PubMed PMID: 3946757.
2. Nandakumar G, Morgan JA, Silverberg $D$, Steinhagen RM. Familial polyposis coli: clinical manifestations, evaluation, management and treatment. Mt Sinai J Med. 2004 Nov;71(6):384-91. PubMed PMID: 15592657.

3. Wheeler M, Mercer D, Grant W, Botha J, Langnas A, Thompson J. Surgical treatment of intra-abdominal desmoid tumors resulting in short bowel syndrome. Cancers. 2012; 4(1):31-38. doi:10.3390/cancers4010031.

4. Cheon SS, Cheah AY, Turley S, Nadesan P, Poon R, Clevers H, Alman BA. beta-Catenin stabilization dysregulates mesenchymal cell proliferation, motility, and invasiveness and causes aggressive fibromatosis and hyperplastic cutaneous wounds. Proc Natl Acad Sci U S A. 2002 May 14;99(10):6973-8.

http://dx.doi.org/10.1073/pnas.10265739 9. Epub 2002 Apr 30. PubMed PMID: 11983872; PubMed Central PMCID: PMC124513. 
5. Signoroni S, Frattini M, Negri T, Pastore $E$, Tamborini E, Casieri $P$, Orsenigo $M$, Da Riva L, Radice P, Sala P, Gronchi A, Bertario L, Pierotti MA, Pilotti S. Cyclooxygenase-2 and platelet-derived growth factor receptors as potential targets in treating aggressive fibromatosis. Clin Cancer Res. 2007 Sep 1;13(17):5034-40. doi: 10.1158/1078-0432.CCR-07-0336.

Erratum in: Clin Cancer Res. $2008 \mathrm{Jul}$ 1;14(13):4354. PubMed PMID: 17785554.

6. Shinagare $A B$, Ramaiya $\mathrm{NH}$, Jagannathan JP, Krajewski KM, Giardino AA, Butrynski JE, Raut CP. A to $Z$ of desmoid tumors. AJR Am J Roentgenol. 2011 Dec;197(6):W100814. doi: 10.2214/AJR.11.6657. PubMed PMID: 22109314.

7. Ross JA, Zhang X. Desmoid-type fibromatosis. In: Atlas of Genetics and Cytogenetics in Oncology and Haematology Atlas. February 2013. Available from: http://AtlasGeneticsOncology.org/Tumor s/DesmoidFibromatosisID5179.html.

8. Kasper B, Ströbel P, Hohenberger P. Desmoid tumors: clinical features and treatment options for advanced disease. Oncologist. 2011;16(5):682-93. doi:10.1634/theoncologist.2010-0281.

Epub 2011 Apr 8. PubMed PMID: 21478276; PubMed Central PMCID: PMC3228186.

9. Messiou C, Chalmers AG, Dexter S. An unusual case of ureteric obstruction. $\mathrm{Br}$ J Radiol. 2005 Sep;78(933):848-50. http://dx.doi.org/10.1259/bjr/62356738.

PubMed PMID: 16110110.

10. Choi JY, Kang KM, Kim BS, Kim TH. Mesenteric fibromatosis causing ureteral stenosis. Korean J Urol. 2010 Jul:51(7):501-4. doi: 10.4111/kju.2010.51.7.501. Epub 2010 Jul 20. PubMed PMID: 20664786; PubMed Central PMCID: PMC2907502.
11. Lath C, Khanna PC, Gadewar SB, Agrawal D. Inoperable aggressive mesenteric fibromatosis with ureteric fistula. Case report and literature review. Eur J Radiol. 2006 Jul;59(1):117-21. http://dx.doi.org/10.1016/j.ejrad.2005.12. 036. Epub 2006 Feb 7. Erratum in: Eur J Radiol. 2006 Dec;60(3):480. PubMed PMID: 16464556.

12. Gari MK, Guraya SY, Hussein AM, Hego MM. Giant mesenteric fibromatosis: Report of a case and review of the literature. World J Gastrointest Surg. 2012 Mar 27;4(3):7982. doi: $10.4240 /$ wjgs.v4.i3.79. PubMed PMID: 22530082; PubMed Central PMCID: PMC3332225.

13. Shah M, Azam B. Case report of an intra-abdominal desmoid tumour presenting with bowel perforation. Mcgill J Med. 2007 Jul;10(2):90-2. PubMed PMID: 18523540; PubMed Central PMCID: PMC2323473.

14. Church J, Lynch C, Neary P, LaGuardia L, Elayi E. A desmoid tumor-staging system separates patients with intraabdominal, familial adenomatous polyposis-associated desmoid disease by behavior and prognosis. Dis Colon Rectum. 2008 Jun;51(6):897-901. doi: 10.1007/s10350-008-9232-5. Epub 2008 Mar 6. PubMed PMID: 18322756.

15. Quintini C, Ward G, Shatnawei A, Xhaja X, Hashimoto K, Steiger E, Hammel J, Diago Uso T, Burke CA, Church JM. Mortality of intra-abdominal desmoid tumors in patients with familial adenomatous polyposis: a single center review of 154 patients. Ann Surg. 2012 Mar;255(3):511-6. doi: 10.1097/SLA.0b013e31824682d4. PubMed PMID: 22323009.

16. Escobar C, Munker R, Thomas JO, Li BD, Burton GV. Update on desmoid tumors. Ann Oncol. 2012 Mar;23(3):5629. doi: 10.1093/annonc/mdr386. Epub 2011 Aug 22. PubMed PMID: 21859899. 
17. Smith AJ, Lewis JJ, Merchant NB, Leung DH, Woodruff JM, Brennan MF. Surgical management of intraabdominal desmoid tumours. $\mathrm{Br} \mathrm{J}$ Surg. $2000 \quad$ May;87(5):608-13. http://dx.doi.org/10.1046/j.13652168.2000.01400.x PubMed PMID: 10792318.

18. Gega $M$, Yanagi $H$, Yoshikawa $R$, Noda M, Ikeuchi $\mathrm{H}$, Tsukamoto K, Oshima $\mathrm{T}$, Fujiwara Y, Gondo N, Tamura K, Utsunomiya J, Hashimoto-Tamaoki T, Yamamura T. Successful chemotherapeutic modality of doxorubicin plus dacarbazine for the treatment of desmoid tumors in association with familial adenomatous polyposis. J Clin Oncol. 2006 Jan 1;24(1):102-5.

http://dx.doi.org/10.1200/JCO.2005.02.1 923 PubMed PMID: 16382119.

19. Fiore $M$, Rimareix $F$, Mariani L, Domont J, Collini P, Le Péchoux C, Casali PG, Le Cesne A, Gronchi A, Bonvalot S. Desmoid-type fibromatosis: a front-line conservative approach to select patients for surgical treatment. Ann Surg Oncol. 2009 Sep;16(9):2587-93. doi: 10.1245/s10434-009-0586-2. Epub 2009 Jul 1. PubMed PMID: 19568815.

20. Nieuwenhuis $M H$, Mathus-Vliegen EM, Baeten CG, Nagengast FM, van der Bijl $J$, van Dalsen $A D$, Kleibeuker $J H$, Dekker E, Langers AM, Vecht J, Peters $\mathrm{FT}$, van Dam $R$, van Gemert WG, Stuifbergen WN, Schouten WR, Gelderblom H, Vasen HF. Evaluation of management of desmoid tumours associated with familial adenomatous polyposis in Dutch patients. $\mathrm{Br} J$ Cancer. 2011 Jan 4;104(1):37-42. doi:10.1038/sj.bjc.6605997. Epub 2010 Nov 9. PubMed PMID: 21063417; PubMed Central PMCID: PMC3039799.
21. Nuyttens JJ, Rust PF, Thomas CR Jr, Turrisi AT 3rd. Surgery versus radiation therapy for patients with aggressive fibromatosis or desmoid tumors: A comparative review of 22 articles. Cancer. 2000 Apr 1;88(7):1517-23. http://dx.doi.org/10.1002/(SICl)10970142(20000401)88:7<1517::AIDCNCR3>3.0.CO;2-9 PubMed PMID: 10738207.

22. Gluck I, Griffith KA, Biermann JS, Feng FY, Lucas DR, Ben-Josef E. Role of radiotherapy in the management of desmoid tumors. Int J Radiat Oncol Biol Phys. 2011 Jul 1;80(3):787-92. doi: 10.1016/j.jrobp.2010.02.053. Epub 2010 Jul 7. PubMed PMID: 20615622.

23. Hansmann A, Adolph C, Vogel T, Unger A, Moeslein G. High-dose tamoxifen and sulindac as first-line treatment for desmoid tumors. Cancer. 2004 Feb 1;100(3):612-20. http://dx.doi.org/10.1002/cncr.11937 PubMed PMID: 14745880.

24. Patel SR, Benjamin RS. Desmoid tumors respond to chemotherapy: defying the dogma in oncology. J Clin Oncol. 2006 Jan 1;24(1):11-2. Epub 2005 Dec 5. http://dx.doi.org/10.1200/JCO.2005.03.6 566 PubMed PMID: 16330666.

25. Janinis J, Patriki M, Vini L, Aravantinos G, Whelan JS. The pharmacological treatment of aggressive fibromatosis: a systematic review. Ann Oncol. 2003 Feb;14(2):181-90. doi: 10.1093/annonc/mdg064 PubMed PMID: 12562642.

26. Vesicoenteric Fistula. Urology Surgery [Internet]. http://urologysurgery.wordpress.com/20 09/01/11/vesicoenteric-fistula/. Accessed on 24.03.2013 
27. Ng TY, Yang MD, Chen YF, Chang $\mathrm{CH}$. Resolution of hydronephrosis due to massive mesenteric fibromatosis using cyclo-oxygenase 2 inhibitors. Urology. 2007 Sep;70(3):591.e3-4. http://dx.doi.org/10.1016/j.urology.2007. 07.025 PubMed PMID: 17905129.

28. Bonvalot S, Desai A, Coppola S, Le Péchoux C, Terrier $P$, Dômont $J$, Le Cesne A. The treatment of desmoid tumors: a stepwise clinical approach. Ann Oncol. 2012 Sep;23 Suppl 10:x15866.

http://dx.doi.org/10.1093/annonc/mds29 8 PubMed PMID: 22987953.
29. Lev D, Kotilingam D, Wei C, Ballo MT, Zagars GK, Pisters PW, Lazar AA, Patel SR, Benjamin RS, Pollock RE. Optimizing treatment of desmoid tumors. J Clin Oncol. 2007 May 1;25(13):1785-91. doi: 10.1200/JCO.2006.10.5015. PubMed PMID: 17470870. 